\title{
The dynamic steroid landscape of equine pregnancy mapped by mass spectrometry
}

\author{
Erin L Legacki, Elizabeth L Scholtz ${ }^{1}$, Barry A Ball ${ }^{2}$, Scott D Stanley ${ }^{3}$, Trish Berger $^{4}$ \\ and Alan J Conley
}

Department of Population Health and Reproduction, School of Veterinary Medicine, University of California, Davis, California 95616, USA, ${ }^{1}$ Department of Population Medicine, Ontario Veterinary College, University of Guelph, Guelph, Ontario, Canada, ${ }^{2}$ Gluck Equine Research Center, Department of Veterinary Science, University of Kentucky, Lexington, Kentucky, USA, ${ }^{3}$ Department of Molecular Biosciences, School of Veterinary Medicine and ${ }^{4}$ Department of Animal Science, University of California, Davis, California, USA

Correspondence should be addressed to A J Conley; Email: ajconley@ucdavis.edu

\begin{abstract}
Liquid chromatography-tandem mass spectrometry (LC-MS/MS) allowed comprehensive analysis of various steroids detectable in plasma throughout equine gestation. Mares $(n=9)$ were bled serially until they foaled. Certain steroids dominated the profile at different stages of gestation, clearly defining key physiological and developmental transitions. The period (weeks 6-20) coincident with equine chorionic gonadotropic (eCG) stimulation of primary corpora lutea and subsequent formation of secondary luteal structures was defined by increased progesterone, $17 \mathrm{OH}$-progesterone and androstenedione, all $\Delta \mathbf{4}$ steroids. The $\mathbf{5} \alpha$-reduced metabolite of progesterone, dihydroprogesterone (DHP) paralleled progesterone secretion at less than half the concentration until week 12 of gestation when progesterone began to decline but DHP concentrations continued to increase. DHP exceeded progesterone concentrations by week 16, clearly defining the luteo-placental shift in pregnane synthesis from primarily ovarian to primarily placental. The period corresponding to the growth of fetal gonads was defined by increasing dehydroepiandrosterone and pregnenolone $(\Delta 5$ steroids) concentrations from week 14, peaking at week 34 and declining to term. Metabolites of DHP (including allopregnanolone) dominated the steroid profile in late gestation, some exceeding DHP by weeks 13 or 14 and near term by almost tenfold. Thus $\Delta 4$ steroids dominated during ovarian stimulation by eCG, inversion of the ratio of progesterone: DHP (increasing $5 \alpha$-pregnanes) marked the luteo-placental shift, $\Delta 5$ steroids defined fetal gonadal growth and $5 \alpha$-reduced metabolites of DHP dominated the steroid profile in mid- to late-gestation. Comprehensive LC-MS/MS steroid analysis provides opportunities to better monitor the physiology and the progress of equine pregnancies, including fetal development.
\end{abstract}

Reproduction (2016) 151 421-430

\section{Introduction}

The endocrinology of equine pregnancy is complex with dramatic changes occurring in a suite of steroid hormones that include pregnanes, androgens and estrogens, appearing in (and many subsequently disappearing from) the maternal circulation at different times. The various patterns observed reflect developmental transitions in steroid synthesis and metabolism in tissue sites that include the maternal ovaries, fetal gonads and the placenta. The maternal ovary is the initial and the principal site of progesterone synthesis in early pregnancy (Squires et al. 1974a, Holtan et al. 1979). The primary corpus luteum synthesizes progesterone (Condon et al. 1979) but, under the influence of equine chorionic gonadotropin (eCG) secreted by the endometrial cups established in early pregnancy (Cole et al. 1931, Allen 1969, Squires et al. 1979), it also synthesizes estrone sulphate (Daels et al. 1990). Luteal tissue weight begins to decline as early as week 7 or 8 (Squires et al. 1979), coincident with regression of the endometrial cups and decreasing eCG (Day \& Rowlands 1940), as the developing allantochorion gradually becomes the major site of progestogenic support for pregnancy (Squires \& Ginther 1975, Holtan et al. 1979). The placenta also synthesizes increasing amounts of estrogen as pregnancy progresses through week 30 (Nett et al. 1973). This coincides with growth of the fetal gonads (Cole et al. 1933) secreting increasing amounts of androgens (MacArthur et al. 1967, Raeside et al. 1973, Raeside 1976, Pashen et al. 1982) that are utilized by the placenta as substrates for estrogen synthesis, functioning as an effective feto-placental unit (Pashen \& Allen 1979, Raeside et al. 1979). The profiles of circulating steroids in pregnant mares are influenced 
by each of these developmental events and can be used to define them.

A variety of techniques have been used to measure steroid concentrations in the pregnant mare (Short 1959, van Niekerk et al. 1973, Smith 1974, Squires et al. 1974a, Burns \& Fleeger 1975, Ganjam et al. 1975, Holtan et al. 1975a, Seren et al. 1981, Tsumagari et al. 1991, Hoffmann et al. 1996). Some investigators utilized assays validated in part by incorporating chromatography in sample preparation (van Niekerk et al. 1973, Barnes et al. 1975, Ganjam et al. 1975, Holtan et al. 1975a, Atkins et al. 1976) to reduce the potential interference from cross-reacting steroids but the resolution of separation was often limited compared with more contemporary chromatographic methods. The introduction and the use of gas chromatography coupled with mass spectrometry (GC-MS) provided both high resolution separation and greater specificity of steroid identification (Holtan et al. 1991, Houghton et al. 1991). To date however, most investigators using GC-MS in studies on steroid secretion during equine pregnancy focused on pregnanes, in particular those representing progesterone metabolites in mid- to late-stages, to better define the virtual disappearance of circulating progesterone in the second half of gestation (Holtan et al. 1991, Ousey et al. 2003). No single study has yet been conducted to investigate the changing profiles of sex steroids from all classes (pregnane, androstane and estranes) that might be predicted to clearly distinguish some of the major ongoing developmental events occurring in the dam and the fetus.

Refinements in, and the use of, mass spectrometry as a tool to analyze multiple steroids with specificity and sensitivity in a single method (Moeller \& Stanley 2012) provides opportunities to better explore the relationships among maternal and fetal steroid hormones. We previously developed a method using liquid chromatographytandem mass spectrometry (LC-MS/MS) to quantify progesterone and its $5 \alpha$-reduced metabolite dihydroprogesterone (DHP) in pregnant mares. These studies also defined their relative progestogenic bioactivities, firmly establishing the physiological significance of DHP in the maintenance of equine pregnancies (Scholtz et al. 2014). The present study was designed to use the same longitudinally-collected series of samples from some of those mares but to expand markedly the number of steroids measured by LC-MS/MS, directed in part by the results of past studies (Holtan et al. 1991, Ousey et al. 2003). The method also included allopregnanolone, a potent neurosteroid of potential importance during fetal development (Brunton et al. 2014), the concentrations of which have been measured in neonatal foals (Aleman et al. 2013) but not previously in pregnant mares to the best of our knowledge. Among those detected with this method, the patterns of secretion of seven different pregnanes and two androgens were established and correlations among their relative concentrations were calculated. Other steroids previously reported to circulate at concentrations that should have been quantifiable with the methods used herein were not found. Specifically, testosterone has been reported to circulate in mares in both early (Daels et al. 1996) and late-gestation (Silberzahn et al. 1984) but was not detected at quantifiable concentrations in the present study, and this also is an observation worthy of note. In all, a comprehensive picture of endocrinology of equine pregnancy emerges to a degree not previously achieved.

\section{Materials and methods}

Animal experiments were approved by the Institutional Animal Use and Care Advisory Committee at the University of California, Davis, in accordance with the Guide for the Care and Use of Agricultural Animals in Agricultural Research and Teaching. Thoroughbred mares $(n=9 ; 10.9 \pm 1.4$ years of age, $500-600$ kg estimated body weight, parity $4.6 \pm 1.2$ ) were bred to Thoroughbred stallions by natural cover. All pregnancies were confirmed as singletons by trans-rectal ultrasound at 14-17 days post-service and heart beats were confirmed at GD24. Jugular blood samples were collected into heparinized tubes every second day for the first 2 months of gestation, then weekly to the sixth month and reduced to once every 4 weeks until parturition. These mares represent a subset of those for which progesterone and DHP have already been reported (Scholtz et al. 2014). Plasma was collected and stored at $-20{ }^{\circ} \mathrm{C}$ for analysis by LC-MS/MS. Negative control plasma was charcoal stripped to remove endogenous steroids and similarly stored at $-20{ }^{\circ} \mathrm{C}$ until used. One mare aborted at gestation day 262. No etiology was ascertained; her pregnancy had been uneventful and apparently healthy until then.

\section{Standards and solutions}

Standards for the analytes examined in this study (see Table 1 and Fig. 1) were purchased from Steraloids (Newport, RI, USA): $17 \alpha$-hydroxyprogesterone (17OH-progesterone), $5 \alpha$-DHP, allopregnanolone $(3 \alpha \mathrm{DHP})$, androstenedione, DHEA, $\mathrm{d}_{7}$-androstendione $\left(A_{4}-d_{7}\right)$, estrone, pregnenolone, $5 \alpha$-pregnan-3 $\beta$, $20 \alpha$-diol $(3 \beta, 20 \alpha$-dihydroxy-dihydroprogesterone $(3 \beta, 20 \alpha$ DHP)), 20 $\alpha$-hydroxy-5 $\alpha$-DHP (20 $\alpha$-hydroxy-dihydroprogesterone $(20 \alpha \mathrm{DHP}))$, progesterone and $d_{9}$-progesterone $\left(P_{4}-d_{9}\right)$. The remaining analytes were purchased from Cerilliant (Round Rock, TX, USA): 19-norandrostenedione, 5 $\alpha$-dihydrotestosterone (DHT), $\mathrm{d}_{3}$-testosterone $\left(\mathrm{T}-\mathrm{d}_{3}\right)$, and testosterone. A master mix of all reference standards was prepared and diluted in methanol (10, $1,0.1$ and $0.01 \mathrm{ng} / \mathrm{ml}$ ). Methanol and water were of HPLC grade and obtained from Burdick and Jackson (Muskegon, MI, USA). Formic acid and methyl-tert buytl ether were of ACS grade and obtained from EMD (Gibbstown, NJ, USA).

\section{Sample preparation}

One milliliter of sample plasma was added to $13 \times 100$ glass screw top tubes followed by the addition of $100 \mu \mathrm{l}$ of the internal standard (IS) mixture $\left(\mathrm{A}_{4}-\mathrm{d}_{7}, T-\mathrm{d}_{3}\right.$ and $\left.\mathrm{P}_{4}-\mathrm{d}_{9}\right)$ in 
Table 1 Steroids investigated and listed by class (pregnanes or C21, androstanes or C19, estranes or C18 steroids) with chemical names and abbreviations used in the text. Note, metabolites of DHP, with the exception of allopregnanolone $(3 \alpha \mathrm{DHP})$, are abbreviated so as to identify them as such (see Fig. 1).

\begin{tabular}{|c|c|c|}
\hline Steroids analyzed & Chemical name & Abbreviations \\
\hline \multicolumn{3}{|l|}{ Pregnanes } \\
\hline Pregnenolone & Pregn-5-ene-3 $\beta$-ol,20-one & \\
\hline Progesterone & Pregn-4-ene-3,20-dione & \\
\hline Dihydroprogesterone & $5 \alpha$-pregnan-3,20-dione & DHP \\
\hline $17 \alpha$-hydroxyprogesterone & Pregn-4-ene-17-ol-3,20-dione & \\
\hline Allopregnanolone & $5 \alpha$-pregnan-3 $\alpha$-ol-20-dione & $(3 \alpha \mathrm{DHP})$ \\
\hline $20 \alpha$-hydroxy DHP & $5 \alpha$-pregnan-20 $\alpha$-ol-3one & $20 \alpha$ DHP \\
\hline $3 \beta, 20 \alpha$-dihydroxy DHP & $5 \alpha$-pregnan- $3 \beta, 20 \alpha$-diol & $3 \beta, 20 \alpha \mathrm{DHP}$ \\
\hline \multicolumn{3}{|l|}{ Androstanes } \\
\hline Dehydroepiandrosterone & Androst-5-ene-3 $\beta$-ol-20-one & DHEA \\
\hline Androstenedione & Androst-4-ene-3,20-dione & \\
\hline Testosterone & Androst-4-ene-17 $\beta$-ol-20-one & \\
\hline Dihydrotestosterone & $5 \alpha$-androstan- $17 \beta$-ol-20-one & DHT \\
\hline \multicolumn{3}{|l|}{ Estranes } \\
\hline Estrone & estra-1,3,5(10)-trien-17-one & \\
\hline 19-norandrostenedione & estr-4-ene-3,17-dione & \\
\hline
\end{tabular}

methanol. Calibrators ranged from $0.1-100 \mathrm{ng} / \mathrm{ml}$ and four levels of quality control (QC) samples (0.6, 1.5. 20 and $80 \mathrm{ng} / \mathrm{ml}$ ) were prepared simultaneously as the samples by adding the standards to charcoal stripped control plasma and processed along with the samples. Five milliliters of methyl-tert buytl ether was added to the $1 \mathrm{ml}$ of plasma and mixed for $15 \mathrm{~min}$ and centrifuged at $3000 \mathrm{~g}$ for $5 \mathrm{~min}$. The resulting supernatant was transferred into a $12 \times 75$ glass tube and dried using a Zymark Turbovap concentrator (Hopkinton, MA, USA) at $45{ }^{\circ} \mathrm{C}$ with $\mathrm{N}_{2}$. Samples were reconstituted with $200 \mu \mathrm{l}$ of 50:50 water and methanol and shaken for $1 \mathrm{~min}$. Calibration standards were run at the beginning and at the end of each sample set with QC samples run daily. Quantitation of analytes was determined by linear regression analysis of the ratio of analyte area to the ratio of area of designated IS. ISs were chosen for each analyte based on closest chemical structure and the analyte retention time. The IS for $17-\mathrm{OH}$-progesterone, 19-norandrostenedione, DHT, testosterone and estrone was $T-d_{3}$, the IS for androstenedione and DHEA was $A_{4}-d_{7}$, and the IS for DHP, $3 \alpha \mathrm{DHP}$, pregnenolone, $3 \beta, 20 \alpha \mathrm{DHP}, 20 \alpha \mathrm{DHP}$ and progesterone was $\mathrm{P}_{4}-\mathrm{d}_{9}$ Two methods were used to analyze the extracted samples. Method I measured $17 \mathrm{OH}$-progesterone, 19-norandrostenedione, DHT, estrone, androstenedione,

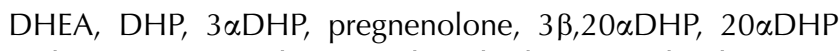
and progesterone. The second method measured only testosterone. Tandem mass spectral detection was developed using a Bruker EVOQ Triple Quadrupole Mass Spectrometer (Billerica, MA, USA) for both methods. Calculations were made using the Bruker Software. A minimum of a six-point calibration curve and a maximum of ten points were used depending on the concentration range of each analyte. Method I was developed to assess a broad range of steroids of all classes. Method II was developed for testosterone alone to optimize the sensitivity of detection over that achieved with the multiple analyte method.

\section{LC-MS/MS analysis}

LC-MS/MS Method I: reverse-phase gradient separation was performed on an Agilent UHPLC C1 8 analytical column (2.1 $\times$ $50 \mathrm{~mm}, 1.8 \mu \mathrm{m} \mathrm{ps}$ ) with two mobile phases delivered at $0.4 \mathrm{ml} / \mathrm{min}$, an injection volume of $20 \mu \mathrm{l}$ and a column temperature of $40{ }^{\circ} \mathrm{C}$. Mobile phase A consisted of water with $0.2 \%$ formic acid. Mobile phase B was methanol. An elution gradient was held at $40 \%$ B for the first $0.2 \mathrm{~min}, 40-60 \%$ B from

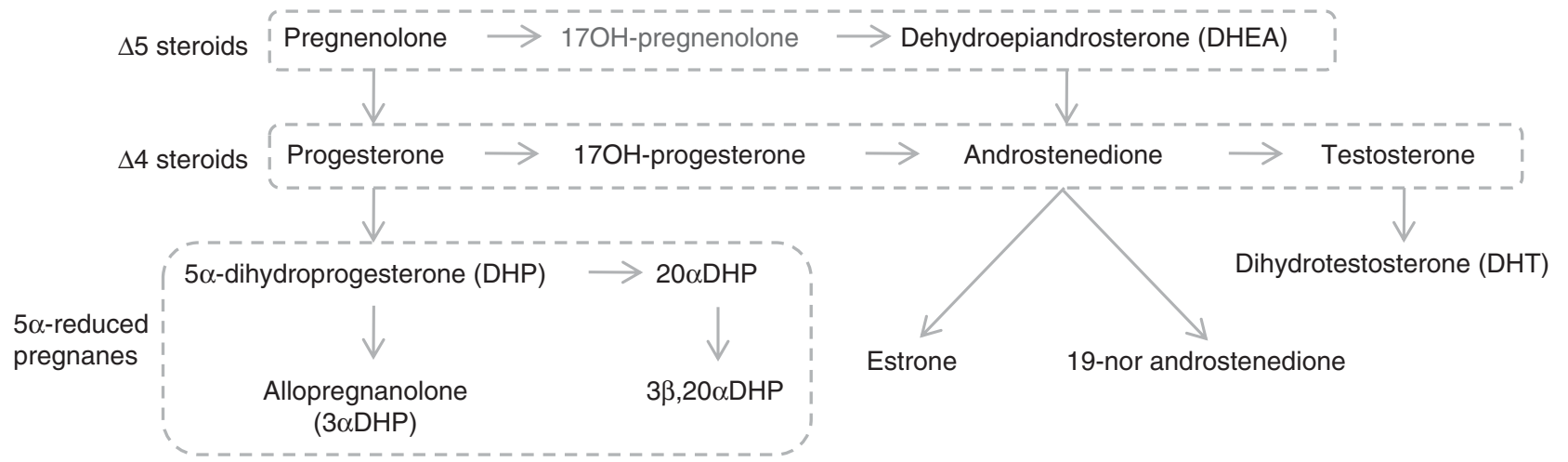

Figure 1 Schematic showing the metabolic relationships among the measured steroids and their chemical similarities; those with a double bond at C-5 ( $\Delta 5$ steroids), a double bond at C-4 ( $\Delta 4$ steroids) and those pregnanes in which the double bond has been reduced ( $5 \alpha-$ reduced pregnanes). Estrone and 19-norandrostenedione (estranes) are also shown as metabolites of androstenedione. 
$0.2-1 \mathrm{~min}, 60-80 \%$ B from $1-10 \mathrm{~min}, 80-90 \% \mathrm{~B}$ from 10.0-10.1 $\mathrm{min}$, held at $90 \% \mathrm{~B}$ from 10.1 to $11.1 \mathrm{~min}, 90-40 \%$ from 11.1 to $11.2 \mathrm{~min}$ and held at $40 \%$ B until $13.10 \mathrm{~min}$. Ionization achieved utilized an atmospheric-pressure chemical ionization $(\mathrm{APCl})$ source. $\mathrm{APCl}$ source conditions for cone gas flow, probe and nebulizer gas flows were held at 25, 25 and 50 arbitrary units of dry nitrogen. The cone and heated probe temperatures were 300 and $450{ }^{\circ} \mathrm{C}$, respectively.

LC-MS/MS Method II: reverse phase gradient separation was performed using an Agilent eclipse XDB-phenyl analytical column $(2.1 \times 150 \mathrm{~mm}, 5 \mu \mathrm{m}$ ps $)$ with two mobile phases delivered at $0.6 \mathrm{ml} / \mathrm{min}$, an injection volume of $20 \mu \mathrm{l}$ and a column temperature of $40{ }^{\circ} \mathrm{C}$. Mobile phase $\mathrm{A}$ was water with $5 \mathrm{mM}$ ammonium fluoride. Mobile phase B was methanol. An elution gradient was held at $50 \%$ B for the first $0.1 \mathrm{~min}$, $50-95 \%$ B from 0.1 to $1 \mathrm{~min}$, held at 95\% B from 1.0 to $2.0 \mathrm{~min}, 95-50 \%$ from 2.0 to $2.1 \mathrm{~min}$ and held at $50 \% \mathrm{~B}$ until $5.0 \mathrm{~min}$. Ionization utilized a heated-electrospray ionization (HESI) source with cone, probe and nebulizer gas flows held at 30, 40 and 65 arbitrary units of dry nitrogen. The cone and heated probe temperatures were 350 and $400{ }^{\circ} \mathrm{C}$.

Tandem mass spectral detection was accomplished using a Bruker EVOQ. Both methods used argon as the collision gas, set to 1.5 arbitrary units. Resolution parameters were set with Q1 and Q3 both at $0.7 \mathrm{~m} / \mathrm{z}$. Detection and quantitation of all analytes were accomplished using multiple reaction monitoring with a minimum of two transitions per analyte. Both methods were validated using assay linearity and inter/intra-assay accuracy and precision (Table 2). Both inter and intra accuracy and precision were assessed at four QC concentrations for all analytes (six replicates). All analytes measured with $\leq 15 \%$ deviation from expected concentrations for the three highest QC concentrations $(1.5,20$ and $80 \mathrm{ng} / \mathrm{ml})$ and $\leq 15 \%$ coefficient of variation ( $\% \mathrm{CV}$ ). For the lowest QC concentration $(0.6 \mathrm{ng} / \mathrm{ml})$ estrone, DHEA, DHT, pregnenolone, $20 \alpha$ DHP and $3 \alpha$ DHP had $\leq 20 \%$ deviation from expected concentrations. All analytes measured had a percent accuracy $(\%$ Acc $)>90 \%$ and a precision $<15 \%$. Accuracy was reported as percent nominal concentration and precision was reported as percent relative s.D. Extraction efficiency (\% EE) was assessed by comparing analyte peak areas from injections of equivalent amounts of analyte with and without liquid-liquid extraction. The efficiency was $>80 \%$ for all of the analytes measured (Table 2). The responses for all analytes were linear and gave correlation coefficients $\left(R^{2}\right)$ of 0.99 or better.

\section{Statistical analysis}

Steroid concentrations from multiple samples per mare within each week of pregnancy were averaged for the week, up to 6 months of gestation and were similarly averaged within each remaining month to term. Weekly and monthly means and standard errors were calculated from these averages across mares. The data from the mare that aborted her pregnancy at GD262 showed no unusual deviation from those of the other mares to that point in pregnancy and were therefore included in the analysis. The 42 and 46 week samples from a second mare had greater than tenfold higher concentrations of pregnenolone than the highest concentrations observed in samples at any stage of gestation from any other mare and all steroid data from these two plasma samples were eliminated from all further analyses. Weekly/monthly concentration of each of the nine measurable steroids was subjected to ANOVA using Proc Mixed in SAS (SAS Statistical Software, SAS Institute Inc., Cary,

Table 2 Method validation: retention times (Rt, $\mathrm{min}$ ), precursor and product ions are shown for the analytes examined (see Table 1 for abbreviations). The transition ions used for quantification are underlined and the most abundant ions are bolded. Parameters listed for each analyte include the limits of detection (LOD, ng/ml) and limits of quantification (LOQ, ng/ml), \% Acc and precision (\% CV) determined at QC 3 (20 ng/ml). The inter assay \% Acc and \% CV were assessed at four QC levels for all analytes; 0.6, 1.5, 20 and $80 \mathrm{ng} / \mathrm{ml}$. All analytes measured with $\leq 15 \%$ deviation from expected concentrations for the three highest QC levels (1.5, 20 and $80 \mathrm{ng} / \mathrm{ml})$ and $\leq 15 \%$ coefficient of variation (\%CV). For the lowest QC level $(0.6 \mathrm{ng} / \mathrm{ml})$ estrone, DHEA, DHT, pregnenolone, $20 \alpha \mathrm{DHP}$ and $3 \alpha \mathrm{DHP}$ had $\leq 20 \%$ deviation from expected concentrations. The average and $\% \mathrm{CV}$ for extraction efficiency ( $\% \mathrm{EE}$ ) was determined for each analyte at each of the QC levels (six replicates) within each compounds quantitation range. $\% \mathrm{EE}=($ analyte peak area with extraction)/(analyte peak area without extraction $) \times 100$.

\begin{tabular}{|c|c|c|c|c|c|c|c|c|c|c|c|}
\hline \multirow[b]{2}{*}{ Compound } & \multirow[b]{2}{*}{ Rt } & \multirow[b]{2}{*}{ Precursor ion } & \multirow[b]{2}{*}{ Production } & \multirow[b]{2}{*}{ LOD } & \multirow[b]{2}{*}{ LOQ } & \multirow[b]{2}{*}{$\% \mathrm{CV}$} & \multirow{2}{*}{\multicolumn{3}{|c|}{$\begin{array}{c}\text { Avg } \% \text { Acc } \% \text { CV } \\
\text { QC } 3-20 \mathrm{ng} / \mathrm{ml}\end{array}$}} & \multirow[b]{2}{*}{$\%$ EE } & \multirow[b]{2}{*}{$\% \mathrm{CV}$} \\
\hline & & & & & & & & & & & \\
\hline 19-norandrostenedione & 1.94 & 273.1 & $197,109,83.1$ & 0.025 & 0.1 & 7. 2 & 19.6 & 98.0 & 5.4 & 96.5 & 5.2 \\
\hline Androstenedione & 2.61 & 287.1 & 97.1, 109, & 0.025 & 0.1 & 3.4 & 20.8 & 104.0 & 7.1 & 95.3 & 5.8 \\
\hline A4-d7 & 2.61 & 294.1 & 100.1, 113.1 & NA & NA & NA & NA & NA & NA & NA & NA \\
\hline Estrone & 2.79 & 271.1 & $253,133,157$ & 0.2 & 0.5 & 4. 6 & 19.0 & 94.8 & 7.1 & 100.0 & 7.1 \\
\hline $\mathrm{T}-\mathrm{d} 3$ & 2.95 & 292.1 & $\mathbf{1 0 9}, 97.1$ & NA & NA & NA & NA & NA & NA & NA & NA \\
\hline DHEA & 3.04 & 289.1 & 271.1, 253. 1, 91. 1 & 0.2 & 0.5 & 5.8 & 18.2 & 91.1 & 8. 3 & 96.1 & 5.7 \\
\hline 17-OH progesterone & 3.25 & 331.2 & $\mathbf{9 7 . 1}, 109,313.1$ & 0.05 & 0.1 & 4. 6 & 19.0 & 95.2 & 10.1 & 100.0 & 6.1 \\
\hline DHT & 3.81 & 291.1 & 255.1, 105.1, 159 & 0.2 & 0.5 & 3.5 & 18.6 & 93.2 & 8. 3 & 89.1 & 4.2 \\
\hline Progesterone & 4.61 & 315.1 & $\mathbf{9 7 . 1}, 109,79.2$ & 0.05 & 0.1 & 2.9 & 20.1 & 100.1 & 5.4 & 91.9 & 4.1 \\
\hline P4-d9 & 4.66 & 324.2 & $\mathbf{1 0 0 . 2}, 113.2$ & NA & NA & NA & NA & NA & NA & NA & NA \\
\hline Pregnenolone & 5.44 & 299.1 & $\mathbf{8 5 . 2}, 159.1,131.1$ & 0.2 & 0.5 & 4. 7 & 20.3 & 101.4 & 7.2 & 100.0 & 4. 3 \\
\hline $3 \beta, 20 \alpha$ DHP & 5.46 & 285.2 & 135.2, 175. 2, 95. 2 & 0.05 & 0.2 & 8.0 & 19.3 & 96.6 & 14.4 & 98.2 & 4.9 \\
\hline $20 \alpha$ DHP & 5.78 & 319.2 & 283.3, 105.2 & 0.2 & 0.5 & 9. 2 & 19.8 & 99.2 & 15.1 & 86.9 & 7.3 \\
\hline DHP & 6.02 & 317.1 & 281.2, 105.2, 119.1 & 0.1 & 0.2 & 4. 6 & 19.3 & 96.3 & 8. 7 & 87.6 & 3.7 \\
\hline Allopregnanolone & 6.14 & 319.1 & 283.1, 257.1 & 0.2 & 0.5 & 6. 4 & 19.7 & 98.3 & 9.7 & 88.1 & 7.0 \\
\hline$T-d 3^{a}$ & 1.87 & 292.1 & $\mathbf{9 7 . 1}, 109.1$ & NA & NA & NA & NA & NA & NA & NA & NA \\
\hline Testosterone $^{\mathrm{a}}$ & 1.87 & 289.1 & $\mathbf{9 7 . 1}, 109,79.2$ & 0.05 & 0.1 & 6. 4 & 20.3 & 101.5 & 8. 5 & 99.1 & 4.7 \\
\hline
\end{tabular}

a Validation parameters for Method II. 


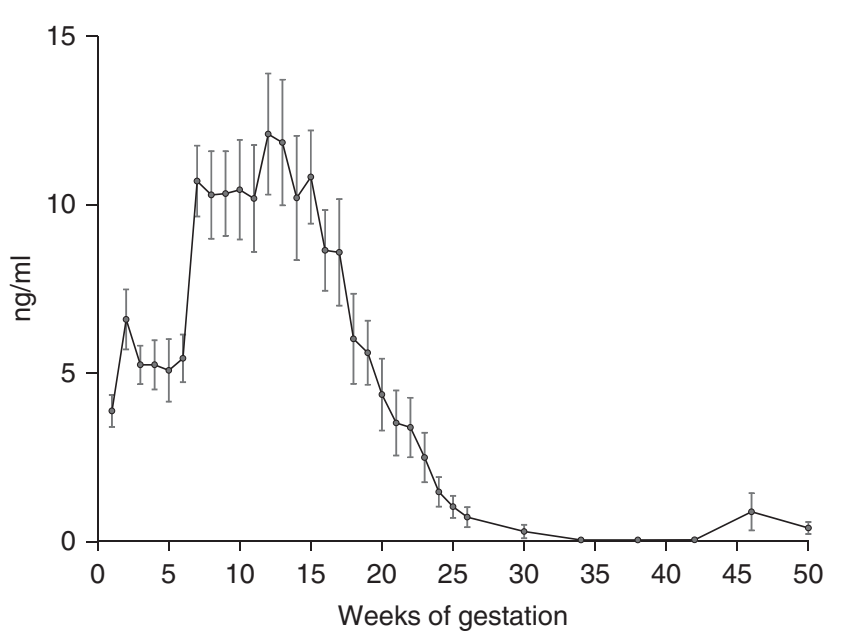

Figure 2 Progesterone concentrations $(\mathrm{ng} / \mathrm{ml})$ measured in maternal serum sampled longitudinally throughout gestation in mares $(n=9)$. Data represent means \pm s.E.M.

NC, USA) with time as a repeated measure. Relationships between values at designated time points were determined with linear contrasts. The correlations among the nine measurable steroids within each mare and the overall correlations for all nine mares were determined with the Proc Corr procedure. The data were graphed using the means and standard errors calculated for each week/month of gestation sampled.

\section{Results}

\section{$\triangle 4$ steroids (progesterone, 17OH-progesterone, androstenedione and testosterone)}

Progesterone concentrations peaked first in the second week post-ovulation at around $7 \mathrm{ng} / \mathrm{ml}$, decreased transiently before rising precipitously from $5.44 \pm 0.71$ to $10.70 \pm 1.05 \mathrm{ng} / \mathrm{ml}$ from week 6 to 7 ( $P<0.01$, Fig. 2 ). Concentrations peaked a second time at almost $12 \mathrm{ng} / \mathrm{ml}$ in week 12 then slowly declined to values that were undetectable in some mares by week 30, reappearing at $\approx 1 \mathrm{ng} / \mathrm{ml}$ in week 46 . $17 \mathrm{OH}$-progesterone concentrations followed a similar, if less well-defined pattern (Fig. 3), increasing from $0.53 \pm 0.15$ in week 5 to $3.19 \pm 0.75 \mathrm{ng} / \mathrm{ml}$ in week $7(P<0.01)$, peaking at $4.12 \pm 0.86 \mathrm{ng} / \mathrm{ml}$ in week 8 . Thereafter, concentrations decreased transiently to $2.94 \pm 0.70 \mathrm{ng} / \mathrm{ml}$ in week 10 $(P<0.05)$ before increasing to a second peak of $4.28 \pm 1.28$ in week $12(P<0.05)$, then declining steadily to $<0.5 \mathrm{ng} / \mathrm{ml}$ in week 23 and $<0.1 \mathrm{ng} / \mathrm{ml}$ after week 34. Androstenedione concentrations were one tenth those of $17 \mathrm{OH}$-progesterone (Fig. 3), increasing from $<0.10 \mathrm{ng} / \mathrm{ml}$ in week 6 to peak at $0.43 \pm 0.09 \mathrm{ng} / \mathrm{ml}$ in week 8 , maintaining these concentrations until week 13, then declining steadily thereafter to $0.05 \mathrm{ng} / \mathrm{ml}$ or less after week 20. Testosterone was below the limits of quantitation (LOQ, $0.10 \mathrm{ng} / \mathrm{ml}$,
Table 2) throughout most of gestation. Testosterone appeared at concentrations of $0.10-0.34 \mathrm{ng} / \mathrm{ml}$ between weeks 6 to 14 in 3 of 5 mares analyzed, coincident with peak concentrations of $17 \mathrm{OH}$-progesterone and androstenedione but was undetectable for the remainder of gestation. All of the three $\Delta 4$ steroids that were readily quantifiable were positively correlated with one another across all of gestation $(+0.35$ to $+0.80, P<0.001)$, and progesterone was most highly correlated with $17 \mathrm{OH}$ progesterone $(+0.8, P<0.05)$ when both peaked in week 8.

\section{$\triangle 5$ steroids (pregnenolone and DHEA)}

Pregnenolone concentrations remained $<1 \mathrm{ng} / \mathrm{ml}$ through week 20. Concentrations began to rise steadily from $0.56 \pm 0.12$ to $3.41 \pm 0.67 \mathrm{ng} / \mathrm{ml}(P<0.01)$ from week 18 to 30, decreasing slowly thereafter. DHEA concentrations were much higher, fluctuating between 1 and $3 \mathrm{ng} / \mathrm{ml}$ in early pregnancy before increasing steadily from $1.19 \pm 0.31$ to a peak of $17.12 \pm 5.61 \mathrm{ng} / \mathrm{ml}$ $(P<0.01)$ between weeks 13 and 34. DHEA concentrations declined steadily thereafter to week 50. Concentrations of pregnenolone and DHEA were positively correlated ( $+0.52, P<0.01$; Fig. 4$)$.

\section{$5 \alpha$-reduced pregnanes (DHP, allopregnanolone, $20 \alpha D H P$ and $3 \beta, 20 \alpha-D H P)$}

DHP concentrations paralleled progesterone at less than half the concentration until week 12 when progesterone began to decline but DHP continued to increase and numerically exceeded progesterone by week 16. DHP concentrations rose from $1.49 \pm 0.21 \mathrm{ng} / \mathrm{ml}$ in the first week of pregnancy to a peak of $37.26 \pm 7.83$ in week

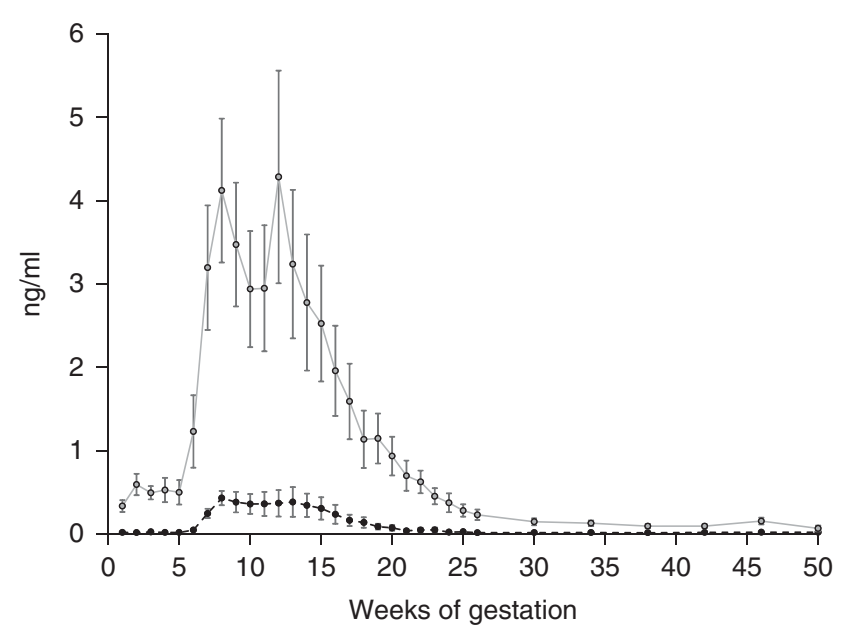

Figure 3 17OH-progesterone (solid line) and androstenedione (broken line) concentrations $(\mathrm{ng} / \mathrm{ml})$ measured in maternal serum sampled longitudinally throughout gestation in mares $(n=9)$. Data represent means \pm S.E.M. 


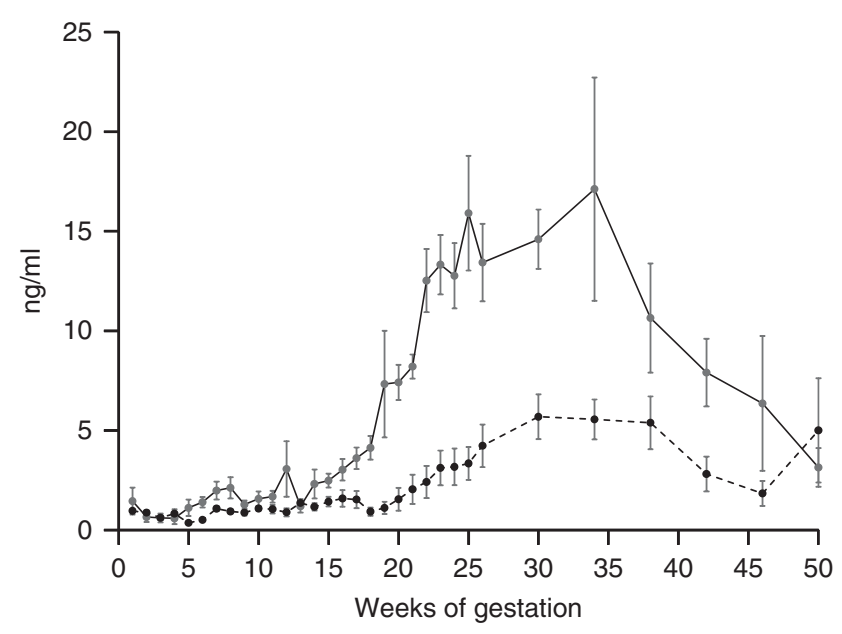

Figure 4 Pregnenolone (broken line) and DHEA (solid line) concentrations $(\mathrm{ng} / \mathrm{ml})$ measured in maternal serum sampled longitudinally throughout gestation in mares $(n=9)$. Data represent means \pm s.E.M.

$50(P<0.01)$. The increase was continuous from week 7 to $30 \quad(4.31 \pm 0.39-31.23 \pm 5.28, \quad P<0.01)$ and, after a transient drop to $25.38 \pm 3.70 \mathrm{ng} / \mathrm{ml}$ at week 34, increased consistently to term. Allopregnanolone concentrations (Fig. 5) rose from $1.05 \pm 0.23$ to $16.02 \pm 4.02(P<0.01)$ from week 9 to 30 , paralleling $\operatorname{DHP}(r=+0.87, P<0.01)$ at slightly less than half the concentration with a pause between weeks 30 and 38, before reaching a peak of almost $20 \mathrm{ng} / \mathrm{ml}$ in week 50 . $20 \alpha \mathrm{DHP}$ was $<1 \mathrm{ng} / \mathrm{ml}$ through week 10 , increased steadily from $5.03 \pm 1.82$ to $69.42 \pm 8.92 \mathrm{ng} / \mathrm{ml}$ $(P<0.01)$ between weeks 13 and 30 , with a secondary rise from $62.22 \pm 6.66$ to $300.18 \pm 100.54 \mathrm{ng} / \mathrm{ml}$ $(P<0.01)$ between weeks 42 and 50 (Fig. 6). The most abundant of the steroids measured in the second half of gestation was $3 \beta, 20 \alpha \mathrm{DHP}$ (Fig. 6). Like $20 \alpha \mathrm{DHP}$, it remained at low concentrations until week $10(1.83 \pm 0.60 \mathrm{ng} / \mathrm{ml})$, increased from $8.56 \pm$ 2.75 to $148.42 \pm 24.28 \mathrm{ng} / \mathrm{ml}(P<0.01)$ between weeks 13 and 30. Concentrations experienced a second increase from $158.66 \pm 23.96$ to $484.19 \pm 121.17$ $(P<0.01)$ between weeks 42 and 50, exceeding DHP concentrations by greater than tenfold. DHP and allopregnanolone were highly correlated $(+0.87$, $P<0.01)$ as were $20 \alpha \mathrm{DHP}$ and $3 \beta, 20 \alpha \mathrm{DHP}(+0.93$, $P<0.01)$. DHP and allopregnanolone $(r=+0.80)$ and $20 \alpha$ DHP and $3 \beta, 20 \alpha \mathrm{DHP}(r=+0.76)$ were also correlated within mares on week 38 but DHP and allopregnanolone were not correlated with $20 \alpha \mathrm{DHP}$ or $3 \beta, 20 \alpha \mathrm{DHP}$ at that stage of pregnancy. The $\Delta 4$ steroids were negatively correlated with both the $\Delta 5$ steroids and the $5 \alpha$-reduced pregnanes $(P<0.05)$.

\section{Estranes (C18)}

Neither unconjugated estrone nor 19-norandrostenedione were found in any samples at the limits of detection of the analytical method used (200 and $25 \mathrm{pg} / \mathrm{ml}$ respectively, Table 2 ).

\section{Discussion}

The concentrations and variable patterns of multiple steroid hormones secreted throughout equine pregnancy, as reported here, provides an unusually complete picture of the physiological transitions occurring from luteal formation to placental steroidogenesis near term. Specifically, the appearance of different steroids earlier and later in gestation help to define distinct developmental phenomena including endometrial cup formation, the luteo-placental shift and the equine feto-placenta unit. For instance, the increase in $17 \mathrm{OH}$-progesterone and androstenedione, together with progesterone, coincided with the expected stimulation of the primary $\mathrm{CL}$ and induction of accessory luteal structures by eCG from the endometrial cups (Allen 1969, Squires et al. 1974a). Previous studies have found strong positive correlations between progesterone and eCG concentrations between weeks 5 and 20 of gestation in mares (Squires, et al. 1979, Hoffmann et al. 1996). The decline in progesterone after week 12 corresponded with the period during which endometrial cups regress and eCG concentrations decline (Allen 1969, Squires et al. 1979). This is also the point at which progesterone and DHP start to diverge. Week 13 was the first week progesterone concentrations began to decline but DHP continued to rise. The rise in DHP as progesterone falls effectively marks the shift from luteal to placental progestogenic support of the pregnancy (the luteo-placental shift) (Holtan et al. 1979). DHP and allopregnanolone continued to increase to term and were highly correlated with increasing $20 \alpha \mathrm{DHP}$ and

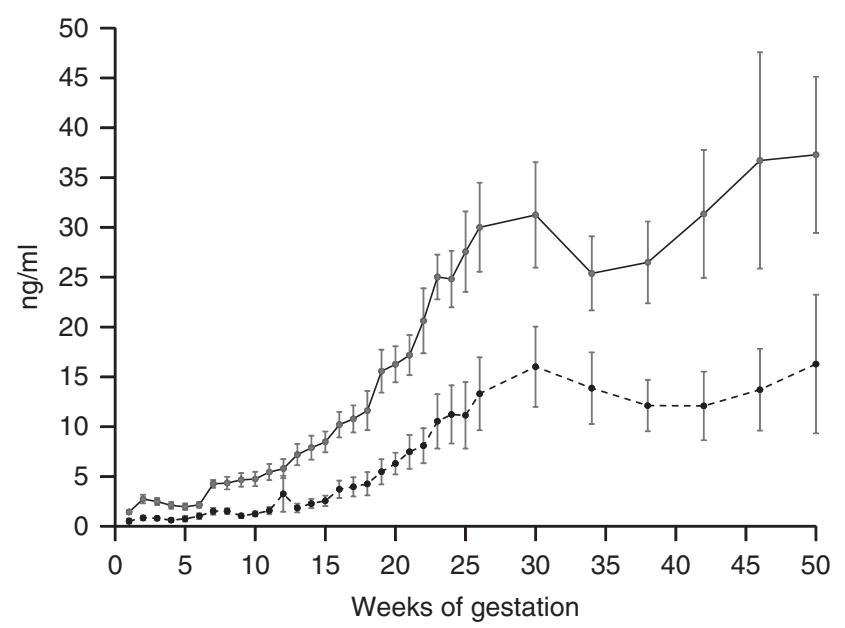

Figure $5 \mathrm{DHP}$ (solid line) and allopregnanolone (broken line) concentrations $(\mathrm{ng} / \mathrm{ml})$ measured in maternal serum sampled longitudinally throughout gestation in mares $(n=9)$.

Data represent means \pm S.E.M. 


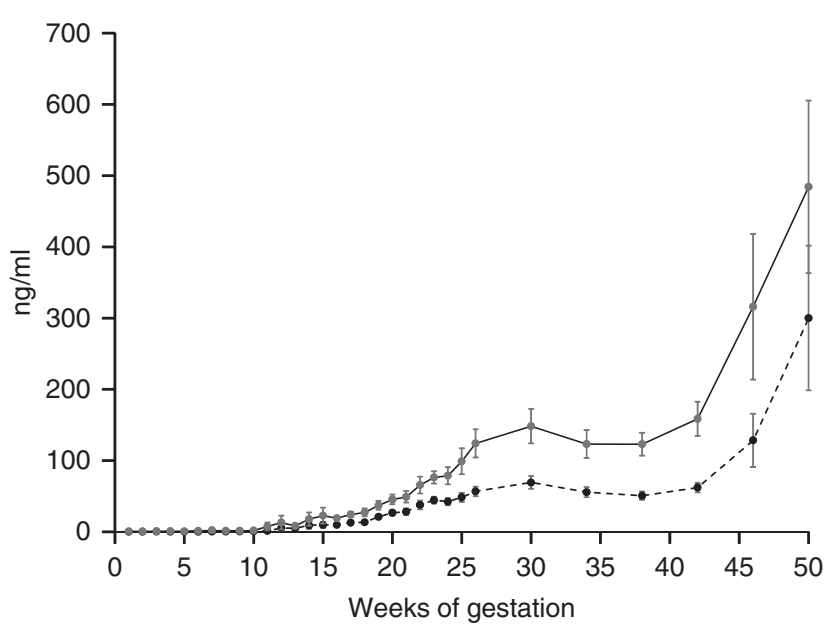

Figure $620 \alpha$-DHP (broken line) and $3 \beta 20 \alpha \mathrm{DHP}$ (solid line) concentrations $(\mathrm{ng} / \mathrm{ml})$ measured in maternal serum sampled longitudinally throughout gestation in mares $(n=9)$.

Data represent means \pm S.E.M.

$3 \beta, 20 \alpha \mathrm{DHP}$ in late gestation, as previously shown (Holtan et al. 1991). Lastly, DHEA and pregnenolone concentrations peaked during the period when the fetal gonads are expected to reach maximum size $(\approx 30$ weeks) before beginning to regress (Wesson \& Ginther 1980). Fetal gonadal androgens fuel placental estrogen synthesis (Pashen \& Allen 1979, Pashen et al. 1982, Raeside 1995), establishing the equine feto-placental unit (Raeside et al. 1979, Mostl 1994). Interestingly, in each case, the steroids involved share a relatively similar basic chemical structure and concentration. Progesterone, $17 \mathrm{OH}$-progesterone and androstenedione are all of the $\Delta 4$ series, and DHEA and pregnenolone are both of the $\Delta 5$ series of steroids (Fig. 1). DHP, allopregnanolone, $20 \alpha \mathrm{DHP}$ and $3 \beta, 20 \alpha \mathrm{DHP}$ are all $5 \alpha$-reduced pregnanes (Fig. 1) and reach concentrations in late-gestation that are orders of magnitude higher in some cases than the $\Delta 4$ and $\Delta 5$ steroids and the magnitude of differences even in peak concentrations is remarkable (androstenedione, $<0.5 \mathrm{ng} / \mathrm{ml} ; 3 \beta, 20 \alpha \mathrm{DHP}$, $>500 \mathrm{ng} / \mathrm{ml}$ ). From this perspective, ovarian stimulation by eCG early in gestation is characterized by increased $\Delta 4$ steroids, fetal gonadal growth in mid-gestation by increased $\Delta 5$ steroids and placental growth and function from mid- to late-gestation by $5 \alpha$-reduced pregnanes, all detectable in maternal blood.

Progesterone was the major focus of initial studies on steroid concentrations in pregnant mares, the earliest reports utilizing chemical methods (Short 1959), competitive protein binding assays (van Niekerk et al. 1973, Smith 1974) and RIA (Squires, et al. 1974b). Discrepancies in results, among those using more careful separation (alongside pregnane standards) (Ganjam et al. 1975, Holtan et al. 1975a) than others (Squires et al. 1974a, Barnes et al. 1975), led to the recognition that at least two cross-reacting steroids caused a gross over-estimate of progesterone concentrations measured in late-gestation (Ganjam et al. 1975, Holtan et al. $1975 a, b)$. Progesterone is in fact extremely low in midto late-gestation in mares, as first proposed by Short (1959). One of the cross-reacting steroids was identified subsequently as DHP in pooled samples taken from late pregnant mares that were analyzed by GC-MS (Atkins et al. 1976). This was confirmed, and additional $5 \alpha$-reduced pregnanes were identified thereafter, by a more comprehensive GC-MS analysis of longitudinal samples from pregnant mares (Holtan et al. 1991). No studies have reported utilizing the specificity afforded by mass spectrometry to analyze pregnanes, androgens and estrogens longitudinally in mares during pregnancy from the time of accessory $\mathrm{CL}$ formation through growth and regression of the fetal gonads that are known to synthesize androgens in considerable amounts (Tait et al. 1983, 1985, Raeside \& Renaud 1985).

The establishment of the endometrial cups around GD37, secretion of eCG and the subsequent stimulation of luteal tissue formation and steroid secretion that follow are well known (Cole et al. 1931, Allen 1969, Squires et al. 1979). However, most studies on steroid secretion examined a limited number analytes and most used immunoassays only. The results presented here confirm the presence and pattern of secretion of $17 \mathrm{OH}$ progesterone in pregnant mares (van Niekerk et al. 1973, Holtan et al. 1975a, Seren et al. 1981), which increases by week 7 with formation of the endometrial cups (Holtan et al. 1975a, Seren et al. 1981), reaching peak concentrations of around $4 \mathrm{ng} / \mathrm{ml}$ by week 8 returning to baseline concentrations after week 20 . This is consistent with ovarian expression of $17 \alpha$-hydroxylase/17,20-lyase cytochrome P450 (P450c17), the enzyme directly responsible for $17 \mathrm{OH}$-progesterone and androgen synthesis (Conley \& Bird 1997, Neto et al. 2010). $\mathrm{P} 450 \mathrm{c} 17$ increases in equine $\mathrm{CL}$ at this time (Albrecht et al. 2001) and its expression is stimulated by eCG (Daels et al. 1998). Interestingly, the increase in $17 \mathrm{OH}$ progesterone concentrations appears to precede that of progesterone by a week but peak at concentrations one third those of progesterone. The current data also confirm a concomitant increase in androstenedione (Daels et al. 1998) which, though one tenth the concentration of $17 \mathrm{OH}$-progesterone, is highly correlated with it and likely provides substrate for the increased secretion of estrone sulphate seen at this point in pregnancy (Evans et al. 1984, Hyland et al. 1984). The detection of testosterone in some mares during this interval is also consistent with the stimulation of $\Delta 4$ steroids in general. These data are equally consistent with the low concentrations of testosterone measured by immuno-assay (Daels et al. 1996) and suggest that the equine CL expresses little $17 \beta$-hydroxysteroid dehydrogenase, the enzyme required for testosterone synthesis. In any case, $17 \mathrm{OH}$-progesterone and androstenedione are more readily measurable, 
providing a more accurate and reliable index of the ovarian response to eCG secretion early in equine pregnancy.

A second major physiological transition is marked by a sustained increase in $\Delta 5$ steroids, namely DHEA and at much lower concentrations pregnenolone, as well as B-ring unsaturated androgens (Tait et al. 1983, 1985, Raeside \& Renaud 1985, Marshall et al. 1999). The increase in DHEA detected in the maternal circulation begins around weeks 13-14 which corresponds well with initiation of growth of the fetal gonads (Walt et al. 1979, Wesson \& Ginther 1980). DHEA is a major product of the fetal gonads (MacArthur et al. 1967, Raeside 1976), and although it fuels estrogen synthesis by the placenta (Bhavnani et al. 1969, Raeside et al. 1979), a surprising amount appears to escape that fate. The concentrations measured by immunoassay in previous studies (Rance \& Park 1978, Pashen et al. 1982) compare favorably to those reported here in terms of both patterns and peak concentrations. Testosterone has been reported to increase during pregnancy, reaching as much as $250 \mathrm{pg} / \mathrm{ml}$ around the time the fetal gonads reach their maximum size (Silberzahn et al. 1984). However, those data were not confirmed by the present results even though $250 \mathrm{pg} / \mathrm{ml}$ was well within the LOQ of the method employed here. Based on the analytical sensitivity of our method, if present, testosterone must remain below $50-100 \mathrm{pg} / \mathrm{ml}$ after regression of the endometrial cups and the decline in eCG secretion. This would suggest that most of what has been detected previously by immuno-assay in the second half of gestation likely represents cross-reacting steroids including DHEA and perhaps B-ring unsaturated androgens, the concentrations of which have not yet been carefully quantified (Tait et al. 1983, Raeside 1995). Similarly, we were unable to detect estrone in maternal plasma at any stage of gestation with limits of detection and quantitation of 0.2 and $0.5 \mathrm{ng} / \mathrm{ml}$ respectively. Others have reported unconjugated estrone concentrations well within this range (Nett et al. 1973, Park et al. 1976, Rance \& Park 1978). However, estrone eluted with equilin and equilenin in the chromatography used by Nett et al. (1973). Additionally, estrone is an expected product of DHEA metabolism, yet estrone and DHEA were not well correlated (Rance \& Park 1978). Thus, present results suggest that immuno-assays for unconjugated estrone are likely confounded by other crossreacting estrogens also. The current data indicate that gonadal growth and endocrine function in the developing fetal foal is characterized by secretion of $\Delta 5$ steroids including DHEA but not testosterone in maternal blood.

The pregnane concentrations reported here include several of the most abundant of those first identified in pregnant mares by Holtan et al. (1991), confirming and comparing favorably with those data, with the exception that $20 \alpha \mathrm{DHP}$ was consistently less than $3 \beta, 20 \alpha \mathrm{DHP}$ in our study. The expected time of endometrial cup formation corresponds with increases in luteal secretion of $\Delta 4$ steroids (progesterone, $17 \mathrm{OH}$-progesterone and androstenedione) in response to eCG. The subsequent shift from luteal to placental support of pregnancy is marked clearly by the decrease in these $\Delta 4$ steroids and an increase in $5 \alpha$-reduced pregnanes. This is a gradual process but DHP concentrations exceed those of progesterone around week 15, as reported previously (Scholtz et al. 2014), and this may be a useful clinical milestone to end progestin treatment of mares suspected of having luteal insufficiency (Allen 2001). The $5 \alpha$-reduced pregnanes rise rapidly thereafter. This includes, and to the best of our knowledge is the first report of, allopregnanolone concentrations in mares. DHP and allopregnanolone reached concentrations comparable with those seen in the third trimester of human pregnancy (Milewich et al. 1975, Stoa \& Bessesen 1975, Hill et al. 2007). Though 6- to 20-fold higher concentrations (120 to $>400 \mathrm{ng} / \mathrm{ml}$ ) may be required to induce signs of anesthesia (Madigan et al. 2012), those observed in pregnant mares are well within concentrations observed in patients reacting to panicinducing stimuli (Eser et al. 2006). It is unclear whether or not allopregnanolone reached concentrations needed to alter neural behavior in these pregnant mares. In any case, allopregnanolone and DHP were among the most highly correlated of any of the steroids measured and the significant negative correlations with $\Delta 4$ pregnanes suggests an increase in $5 \alpha$-reductase expression and activity in the placenta (Scholtz et al. 2014) as the allanto-chorion develops and matures. The increase in other $5 \alpha$-reduced metabolites of DHP, $20 \alpha \mathrm{DHP}$ and $3 \beta, 20 \alpha \mathrm{DHP}$, accelerates toward term and suggests increased expression of additional oxidoreductases in the placenta before parturition. The developmental changes in expression of steroid metabolizing enzymes in the equine placenta merits investigation. The comprehensive analysis of changes in steroid profiles during equine gestation presented here establishes a better understanding of the underlying physiology of pregnancy, and perhaps suggests diagnostic opportunities for better assessing it.

\section{Declaration of interest}

The authors declare that there is no conflict of interest that could be perceived as prejudicing the impartiality of the research reported.

\section{Funding}

This work was supported by the John P Hughes Endowment and the Floyd and Mary Schwall Fellowship in Medical Research. The funders had no role in the study design, data collection and analysis, decision to publish, or preparation of the manuscript. 


\section{Acknowledgements}

The authors gratefully acknowledge the John P Hughes Endowment for funding and the Floyd and Mary Schwall Fellowship in Medical Research for additional support (ELS). The authors also wish to express gratitude to the technical staff of the Equine Analytical Chemistry Laboratory, School of Veterinary Medicine, University of California, Davis, whose expertise and guidance was instrumental in the successful completion of the project. We specifically wish to acknowledge Daniel McKemie, Teresa Bowers, Go Sugiarto and Sandy Yim for providing training and support.

\section{References}

Albrecht BA, MacLeod JN \& Daels PF 2001 Expression of 3 $\beta$-hydroxysteroid dehydrogenase, cytochrome p450 $17 \alpha$-hydroxylase/17,20-lyase and cytochrome p450 aromatase enzymes in corpora lutea of diestrous and early pregnant mares. Theriogenology 55 551-561. (doi:10.1016/ S0093-691X(01)00425-3)

Aleman M, Pickles KJ, Conley AJ, Stanley S, Haggett E, Toth B \& Madigan JE 2013 Abnormal plasma neuroactive progestagen derivatives in ill, neonatal foals presented to the neonatal intensive care unit. Equine Veterinary Journal 45 661-665. (doi:10.1111/evj.12065)

Allen WR 1969 The immunological measurement of pregnant mare serum gonadotrophin. Journal of Endocrinology 43 593-598. (doi:10.1677/joe. 0.0430593)

Allen WR 2001 Luteal deficiency and embryo mortality in the mare. Reproduction in Domestic Animals 36 121-131. (doi:10.1046/j.14390531.2001.d01-43.x)

Atkins DT, Harms PG, Sorensen AM Jr \& Fleeger JL 1976 Isolation, identification and quantitation of serum $5 \alpha$-pregnane-3,20-dione and its relationship to progesterone in the pregnant mare. Steroids 28 867-880. (doi:10.1016/0039-128X(76)90036-2)

Barnes RJ, Nathanielsz PW, Rossdale PD, Comline RS \& Silver M 1975 Plasma progestagens and oestrogens in fetus and mother in late pregnancy. Journal of Reproduction and Fertility. Supplement 617-623.

Bhavnani BR, Short RV \& Solomon S 1969 Formation of estrogens by the pregnant mare. I. Metabolism of 7-3H-dehydroisoandrosterone and 4-14C-androstenedione injected into the umbilical vein. Endocrinology 85 1172-1179. (doi:10.1210/endo-85-6-1172)

Brunton PJ, Russell JA \& Hirst JJ 2014 Allopregnanolone in the brain: protecting pregnancy and birth outcomes. Progress in Neurobiology 113 106-136. (doi:10.1016/j.pneurobio.2013.08.005)

Burns SJ \& Fleeger JL 1975 Plasma progestagens in the pregnant mare in the first and last 90 days of gestation. Journal of Reproduction and Fertility. Supplement 435-439.

Cole HH, Howell CE \& Hart GH 1931 The changes occurring in the ovary of the mare during pregnancy. Anatomical Record 49 199-209. (doi:10. 1002/ar.1090490305)

Cole HH, Hart GH, Lyons WR \& Catchpole HR 1933 The development and hormonal content of fetal horse gonads. Anatomical Record 59 275-293. (doi:10.1002/ar.1090560308)

Condon WA, Ganjam VK \& Kenney RM 1979 Catecholamines and equine luteal progestagens. Journal of Reproduction and Fertility. Supplement 199-203.

Conley AJ \& Bird IM 1997 The role of cytochrome P450 $17 \alpha$-hydroxylase and $3 \beta$-hydroxysteroid dehydrogenase @in the integration of gonadal and adrenal steroidogenesis via the delta 5 and delta 4 pathways of steroidogenesis in mammals. Biology of Reproduction 56 789-799. (doi:10.1095/biolreprod56.4.789)

Daels PF, Shideler S, Lasley BL, Hughes JP \& Stabenfeldt GH 1990 Source of oestrogen in early pregnancy in the mare. Journal of Reproduction and Fertility 90 55-61. (doi:10.1530/jrf.0.0900055)

Daels PF, Chang GC, Hansen B \& Mohammed HO 1996 Testosterone secretion during early pregnancy in mares. Theriogenology 45 1211-1219. (doi:10.1016/0093-691X(96)00076-3)
Daels PF, Albrecht BA \& Mohammed HO 1998 Equine chorionic gonadotropin regulates luteal steroidogenesis in pregnant mares. Biology of Reproduction 59 1062-1068. (doi:10.1095/biolreprod59.5.1062)

Day FT \& Rowlands IW 1940 The time and rate of appearance of gonadotrophin in the serum of pregnant mares. Journal of Endocrinology 2 255-261. (doi:10.1677/joe.0.0020255)

Eser D, Romeo E, Baghai TC, di Michele F, Schule C, Pasini A, Zwanzger P, Padberg F \& Rupprecht R 2006 Neuroactive steroids as modulators of depression and anxiety. Neuroscience 138 1041-1048. (doi:10.1016/j. neuroscience.2005.07.007)

Evans KL, Kasman LH, Hughes JP, Couto M \& Lasley BL 1984 Pregnancy diagnosis in the domestic horse through direct urinary estrone conjugate analysis. Theriogenology 22 615-620. (doi:10.1016/0093691X(84)90489-8)

Ganjam VK, Kenney RM \& Flickinger G 1975 Plasma progestagens in cyclic, pregnant and post-partum mares. Journal of Reproduction and Fertility. Supplement 441-447.

Hill M, Cibula D, Havlikova H, Kancheva L, Fait T, Kancheva R, Parizek A \& Starka L 2007 Circulating levels of pregnanolone isomers during the third trimester of human pregnancy. Journal of Steroid Biochemistry and Molecular Biology 105 166-175. (doi:10.1016/j. jsbmb.2006.10.010)

Hoffmann B, Gentz F \& Failing K 1996 Investigations into the course of progesterone, oestrogen and eCG concentrations during normal and impaired pregnancy in the mare. Reproduction in Domestic Animals 31 717-723. (doi:10.1111/j.1439-0531.1996.tb01444.x)

Holtan DW, Nett TM \& Estergreen VL 1975a Plasma progestins in pregnant, postpartum and cycling mares. Journal of Animal Science 40 251-260. (doi:10.2134/jas1975.402251x)

Holtan DW, Nett TM \& Estergreen VL 1975b Plasma progestagens in pregnant mares. Journal of Reproduction and Fertility. Supplement 419-424.

Holtan DW, Squires EL, Lapin DR \& Ginther OJ 1979 Effect of ovariectomy on pregnancy in mares. Journal of Reproduction and Fertility. Supplement 457-463.

Holtan DW, Houghton E, Silver M, Fowden AL, Ousey J \& Rossdale PD 1991 Plasma progestagens in the mare, fetus and newborn foal. Journal of Reproduction and Fertility. Supplement 44 517-528.

Houghton E, Holtan D, Grainger L, Voller BE, Rossdale PD \& Ousey JC 1991 Plasma progestagen concentrations in the normal and dysmature newborn foal. Journal of Reproduction and Fertility. Supplement $\mathbf{4 4}$ 609-617.

Hyland JH, Wright PJ \& Manning SJ 1984 An investigation of the use of plasma oestrone sulphate concentrations for the diagnosis of pregnancy in mares. Australian Veterinary Journal 61 123. (doi:10.1111/j.17510813.1984.tb07205.x)

MacArthur E, Short RV \& O'Donnell VJ 1967 Formation of steroids by the equine foetal testis. Journal of Endocrinology 38 331-336. (doi:10.1677/ joe.0.0380331)

Madigan JE, Haggettt EF, Pickles KJ, Conley A, Stanley S, Moeller B, Toth B \& Aleman M 2012 Allopregnanolone infusion induced neurobehavioural alterations in a neonatal foal: is this a clue to the pathogenesis of neonatal maladjustment syndrome? Equine Veterinary Journal. Supplement 109-112. (doi:10.1111/j.2042-3306.2011.00504.x)

Marshall DE, Gower DB, Silver M, Fowden A \& Houghton E 1999 Cannulation in situ of equine umbilicus. Identification by gas chromatography-mass spectrometry (GC-MS) of differences in steroid content between arterial and venous supplies to and from the placental surface. Journal of Steroid Biochemistry and Molecular Biology 68 219-228. (doi:10.1016/S0960-0760(99)00034-5)

Milewich L, Gomez-Sanchez C, Madden JD \& MacDonald PC 1975 Isolation and characterization of $5 \alpha$-pregnane-3,20-dione and progesterone in pepipheral blood of pregnant women. measurement throughout pregnancy. Gynecologic Investigation 6 291-306. (doi:10. 1159/000301525)

Moeller BC \& Stanley SD 2012 The development and validation of a turbulent flow chromatography-tandem mass spectrometry method for the endogenous steroid profiling of equine serum. Journal of Chromatography. B, Analytical Technologies in the Biomedical and Life Sciences 905 1-9. (doi:10.1016/j.jchromb.2012.06.021)

Mostl E 1994 The horse feto-placental unit. Experimental and Clinical Endocrinology 102 166-168. (doi:10.1055/s-0029-1211277) 
Neto AC, Ball BA, Browne P \& Conley AJ 2010 Cellular localization of androgen synthesis in equine granulosa-theca cell tumors: immunohistochemical expression of $17 \alpha$-hydroxylase/17,20-lyase cytochrome P450. Theriogenology 74 393-401. (doi:10.1016/j.theriogenology. 2010.02.022)

Nett TM, Holtan DW \& Line EV 1973 Plasma estrogens in pregnant and postpartum mares. Journal of Animal Science 37 962-970. (doi:10.2134/ jas1973.374962x)

van Niekerk CH, Morgenthal JC, Sanders CP \& Malan JE 1973 Progesterone concentration in the peripheral plasma of the mare during the oestrous cycle and early pregnancy. Journal of the South African Veterinary Association 44 363-373.

Ousey JC, Forhead AJ, Rossdale PD, Grainger L, Houghton E \& Fowden AL 2003 Ontogeny of uteroplacental progestagen production in pregnant mares during the second half of gestation. Biological Reproduction 69 540-548. (doi:10.1095/biolreprod.102.013292)

Park BK, Rance TA \& Dean PD 1976 A radioimmunoassay for equilin in equine pregnancy plasma. FASEB Letters 72 18-20. (doi:10.1016/00145793(76)80888-5)

Pashen RL \& Allen WR 1979 The role of the fetal gonads and placenta in steroid production, maintenance of pregnancy and parturition in the mare. Journal of Reproduction and Fertility. Supplement 499-509.

Pashen RL, Sheldrick EL, Allen WR \& Flint AP 1982 Dehydroepiandrosterone synthesis by the fetal foal and its importance as an oestrogen precursor. Journal of Reproduction and Fertility. Supplement 32 389-397.

Raeside JI 1976 Dehydroepiandrosterone in the fetal gonads of the horse. Journal of Reproduction Fertility 46 423-425. (doi:10.1530/jrf.0. 0460423)

Raeside JI 1995 Steroid production by equine fetal gonads: a speculative view. Equine Veterinary Journal 27 324-325. (doi:10.1111/j.2042-3306. 1995.tb04065.x)

Raeside JI \& Renaud RL 1985 Identification of 3 $\beta$-hydroxy-5,7-androstadien-17-one as a secretory product of the fetal horse gonad in vivo and in vitro. Journal of Endocrinology 107 415-419. (doi:10.1677/joe.0. 1070415)

Raeside JI, Liptrap RM \& Milne FJ 1973 Relationship of fetal gonads to urinary estrogen excretion by the pregnant mare. American Journal of Veterinary Research 34 843-845.

Raeside JI, Liptrap RM, McDonell WN \& Milne FJ 1979 A precursor role for DHA in a feto-placental unit for oestrogen formation in the mare. Journal of Reproduction and Fertility. Supplement 493-497.

Rance TA \& Park BK 1978 The measurement of oestrone, equilin and dehydroepiandrosterone in the peripheral plasma of pregnant pony mares by radioimmunoassay. Journal of Steroid Biochemistry 9 1065-1069. (doi:10.1016/0022-4731(78)90033-X)

Scholtz EL, Krishnan S, Ball BA, Corbin CJ, Moeller BC, Stanley SD, McDowell KJ, Hughes AL, McDonnell DP \& Conley AJ 2014 Pregnancy without progesterone in horses defines a second endogenous biopotent progesterone receptor agonist, 5 $\alpha$-dihydroprogesterone. PNAS 111 3365-3370. (doi:10.1073/pnas.1318163111)
Seren E, Tamanini C, Gaiani R \& Bono G 1981 Concentrations of progesterone, $17 \alpha$-hydroxyprogesterone and $20 \alpha$-dihydroprogesterone in the plasma of mares during pregnancy and at parturition. Journal of Reproduction and Fertility 63 443-448. (doi:10.1530/jrf.0.0630443)

Short RV 1959 Progesterone in blood. IV. Progesterone in the blood of mares. Journal of Endocrinology 19 207-210. (doi:10.1677/joe.0.0190207)

Silberzahn P, Zwain I \& Martin B 1984 Concentration increase of unbound testosterone in plasma of the mare throughout pregnancy. Endocrinology 115 416-419. (doi:10.1210/endo-115-1-416)

Smith ID 1974 Progesterone concentrations in the peripheral plasma of the mare during pregnancy. Research in Veterinary Science 16 114-116.

Squires EL \& Ginther OJ 1975 Collection technique and progesterone concentration of ovarian and uterine venous blood in mares. Journal of Animal Science 40 275-281. (doi:10.2134/jas1975.402275x)

Squires EL, Wentworth BC \& Ginther OJ 1974 a Progesterone concentration in blood of mares during the estrous cycle, pregnancy and after hysterectomy. Journal of Animal Science 39 759-767. (doi:10.2134/ jas1974.394759x)

Squires EL, Douglas RH, Steffenhagen WP \& Ginther OJ 1974b Ovarian changes during the estrous cycle and pregnancy in mares. Journal of Animal Science 38 330-338. (doi:10.2134/jas1974.382330x)

Squires EL, Stevens WB, Pickett BW \& Nett TM 1979 Role of pregnant mare serum gonadotropin in luteal function of pregnant mares. American Journal of Veterinary Research 40 889-891.

Stoa KF \& Bessesen A 1975 Identification and quantitation of $5 \alpha$-pregnanedione in human pregnancy plasma. Journal of Steroid Biochemistry 6 1-25. (doi:10.1016/0022-4731(75)90024-2)

Tait AD, Santikarn S \& Allen WR 1983 Identification of $3 \beta$-hydroxy-5,7pregnadien-20-one and $3 \quad \beta$-hydroxy-5,7-androstadien-17-one as endogenous steroids in the fetal horse gonad. Journal of Endocrinology 99 87-92. (doi:10.1677/joe.0.0990087)

Tait AD, Hodge LC \& Allen WR 1985 The biosynthesis of $3 \beta$-hydroxy-5,7androstadien-17-one by the horse fetal gonad. FASEB Letters $\mathbf{1 8 2}$ 107-110. (doi:10.1016/0014-5793(85)81164-9)

Tsumagari S, Higashino T, Takagi K, Ohba S, Satoh S \& Takeishi M 1991 Changes of plasma concentrations of steroid hormones, prostaglandin F2 $\alpha$-metabolite and pregnant mare serum gonadotropin during pregnancy in thoroughbred mares. Journal of Veterinary Medical Science $\mathbf{5 3}$ 797-801. (doi:10.1292/jvms.53.797)

Walt ML, Stabenfeldt GH, Hughes JP, Neely DP \& Bradbury R 1979 Development of the equine ovary and ovulation fossa. Journal of Reproduction and Fertility. Supplement 471-477.

Wesson JA \& Ginther OJ 1980 Fetal and maternal gonads and gonadotropins in the pony. Biological Reproduction 22 735-743. (doi:10.1095/biolreprod22.4.735)

Received 18 November 2015

First decision 4 January 2016

Revised manuscript received 13 January 2016

Accepted 26 January 2016 